\title{
Discussion remarks on the role of wood and chitin constituents during carbonization
}

\author{
Anna IInicka and Jerzy P. Lukaszewicz* \\ Faculty of Chemistry, Nicolaus Copernicus University, Torun, Poland
}

Edited by:

Tomás Cordero, Universidad de

Málaga, Spain

Reviewed by:

Leszek A. Czepirski, AGH University

of Science and Technology, Poland

Lei Zhang, Tianjin University, China

${ }^{*}$ Correspondence:

Jerzy P. Lukaszewicz, Faculty of

Chemistry, Nicolaus Copernicus

University, ul. Gagarina 11, Torun

87-100, Poland

e-mail: jerzy_lukaszewicz@o2.pl

\begin{abstract}
Nature is a source of some biomaterials like wood and chitin, which can be successfully transformed into chars of advanced structural/surface parameters. The manuscript is discursive and suggests that particular components of the materials (cellulose, lignin, hemicellulose, alfa-chitin fibrils, mineral-protein matrix) play a specific role in the manufacturing of porous chars. It is proposed that some of the components (hemicellulose and mineral-protein matrixes) behave like a natural soft template during carbonization of wood and chitin. It is suggested why particular components and derivatives of wood and chitin (cellulose and chitosan) can not form porous carbonaceous matrixes when are carbonized separately.
\end{abstract}

Keywords: wood, cellulose, chitin, chitosan, pyrolysis

\section{DISCUSSION}

Activated carbons may be generally described as high-surface area solids with predominant presence of carbon atoms. High-surface area usually comes in line with well developed pore structure (total pore volume, properly tailored pore size distribution), which enable the applicability of such a carbons like selective adsorption from gas or liquid phase and/or heterogeneous catalyst. Besides well-developed structural parameters, the term "activation" in case of carbons may be associated with chemical heterogeneity of the surface (surface functional groups, inserted heteroatoms, surface heterogenic clusters, etc.), which additionally influence the applicability of such activated carbons. However, surface properties given to the carbons by even intensive chemical modification of the surface, will be suppressed in practical applications if structural parameters like specific surface area and pore structure are not properly developed, i.e., are not high enough. Therefore, development of the structural parameters seems to be of primary importance and should be the main target in fabrication of any activated carbon. If carbonized, some materials yield porous matrixes instantly and no activation is needed to achieve developed structural parameters.

Activated carbons or let better say high-surface area carbonaceous matrixes can be fabricated in different manners using natural and synthetic precursors. Among natural raw materials, lignin-cellulose materials play a crucial role in the industrial and laboratory fabrication practice. Such materials, particularly wood of different sort, are commonly applied in activated carbon fabrication. Literature quotes such types of wood like: pine, oak, beech, birch, willow, bamboo, etc. (Cyganiuk et al., 2012; Schröder et al., 2011). Besides them other cellulose-based raw materials are also in use: coconut shell, fruit stone (Aygün et al., 2003; Daifullah and Girgis, 2003). A simple heat-treatment of such precursor with no access of oxidative media leads instantly to carbon-type materials (chars) of relatively high-surface area like $100-500 \mathrm{~m}^{2} / \mathrm{g}$. This parameter may be upgraded by means of various activations (chemical or physical). Such obtained chars owe the high-surface area to the presence of slit-like pores of differentiated size (Figure 1).

Looking on the above listed successful research attempts as well as industrial practice in activated carbon fabrication, one could expect that also carbonization of pure cellulose might yield chars, which due to the purity of the raw material should be free from some undesired and uncontrolled impurities like some metal atoms. The atoms (sodium, potassium, magnesium, calcium, aluminum, traces of transition metals) are usually present in wood-driven chars/activated carbons since they are always present in plant tissues and do not evaporate during the heattreatment of such a biomass. The impurity elements can be recovered from carbon/wood in form of ash after combustion in oxygen.

However, the expectation that pure cellulose can be easily converted to a porous char does not consider the real phenomena occurring during carbonization of wood. Generally, fabrication of some high-surface area and porous materials like silica and synthetic activated carbons from non-composite and non-structured precursors can be spectacularly supported by application of so called templates (Liu et al., 2007; Zhang et al., 2009). Template is a substance (organic or inorganic), which should be added at a primary stages of porous solid fabrication to a suitable precursor. After that such enriched precursor is usually transformed into a final product, for example, by means of carbonization. So called soft templates self-disappear during the transformation due to decomposition and/or evaporation. The vanishing of soft templates must be synchronized with the build-up of a solid matrix made of a target substance like elemental carbon, $\mathrm{SiO}_{2}$, etc. In such cases, vanishing template opens empty spaces in the already built matrix, which can significantly contribute to total surface area and total pore volume since the cavities are accessible to atoms/molecules in gas and liquid phase (adsorption). On the contrary, hard templates remain in a newly formed solid matrix. Thus, such hard templates must be removed usually by dissolution 
in water, organic solvents, and a solution of aggressive media like water solution of strong mineral acids. To achieve the expected effect, i.e., enhanced structural parameters of a solid, template substance must be properly dispersed in a solid phase precursor. Several options are possible (Figure 2).

Thus, formation of different geometric forms of carbon-based matrixes is possible. Different organic precursors of carbon matrix can be applied. The following materials have been tested: furfuryl alcohol, phenol-formaldehyde resin, sucrose, acrylonitrile, vinyl acetate, pyrrole, glucose, xylose, phenolic resin, divinylbenzene, petroleum pitch, mesophase pitch, polyvinyl chloride, naphthalene, anthracene, pyrene, acenaphthene, triblock copolymers, mixture of phloroglucinol, and formaldehyde.

After a comprehensive consideration of some basic aspects of the template method, a fundamental question should be

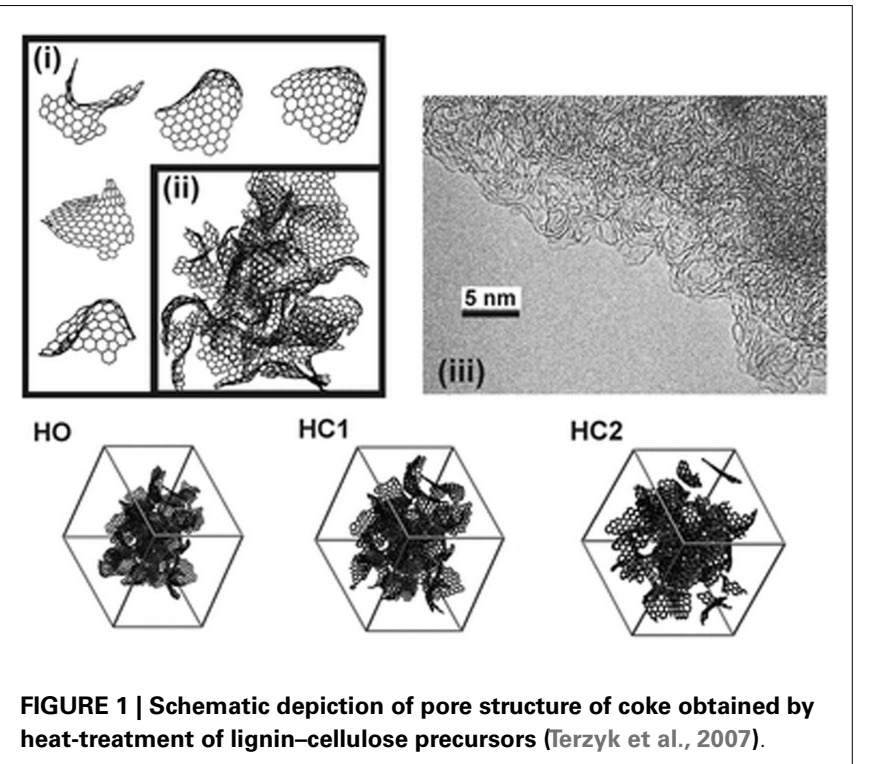

answered if the method refers somehow to the fabrication of high-surface area chars from plain wood. The process is known because of instant achievement of relatively advanced structural parameters even without any activation. The answer to the question may involve the analysis of microscopic structure of wood (Figure 3).

In general, wood consists of hemicellulose, cellulose, lignin, various proteins, and extractants, i.e., some chemicals absorbed in wood during the growing cycle (usually below $3 \%$ by weight). Parallel cellulose fibers are cross-linked by hemicellulose, protein, and lignin moieties. Such a 3D structure has a high mechanical strength and may by is porous. The structure somehow resembles the structure of an automobile tire where iron cord (replaced by cellulose fibers) is stacked by a rubber binder (replaced by lignin/hemicellulose moieties). Cellulose differs from lignin, proteins, and hemicellulose regarding their thermal resistance. Heat-treatment of wood first releases water and volatile organic compounds, which are produced in the volatilization of basic wood components. At around $150-160^{\circ} \mathrm{C}$ wood looses moisture in all forms (Roberts, 1971). Over the temperature range 200$280^{\circ} \mathrm{C}$ hemicellulose decomposes intensively yielding several basic products like carbon dioxide, carbon monoxide, and condensable vapors. After the removal of hemicellulose, cellulose rods are weakly bonded to each other and wood becomes brittle. At increasing temperatures, hemicellulose and lignin start to decompose slightly earlier (begins at ca. $180^{\circ} \mathrm{C}$, maximum at ca. $400^{\circ} \mathrm{C}$ ) then cellulose (begins at ca. $220^{\circ} \mathrm{C}$, maximum at ca. $380^{\circ} \mathrm{C}$ ). The given temperatures should be treated as rather rough values since the may depend on many factors. Lignin and cellulose upon heattreatment release relatively large amount of water, carbon dioxide, carbon monoxide, formic acid, and more complex organic molecules, which later condensate to tar. In summary, wood may be described as composition of carbon matrix precursors (cellulose and lignin) and soft organic templates (natural templates - hemicellulose and proteins). During carbonization, the natural templates vanish as artificial soft templates. Generally, the cellulose

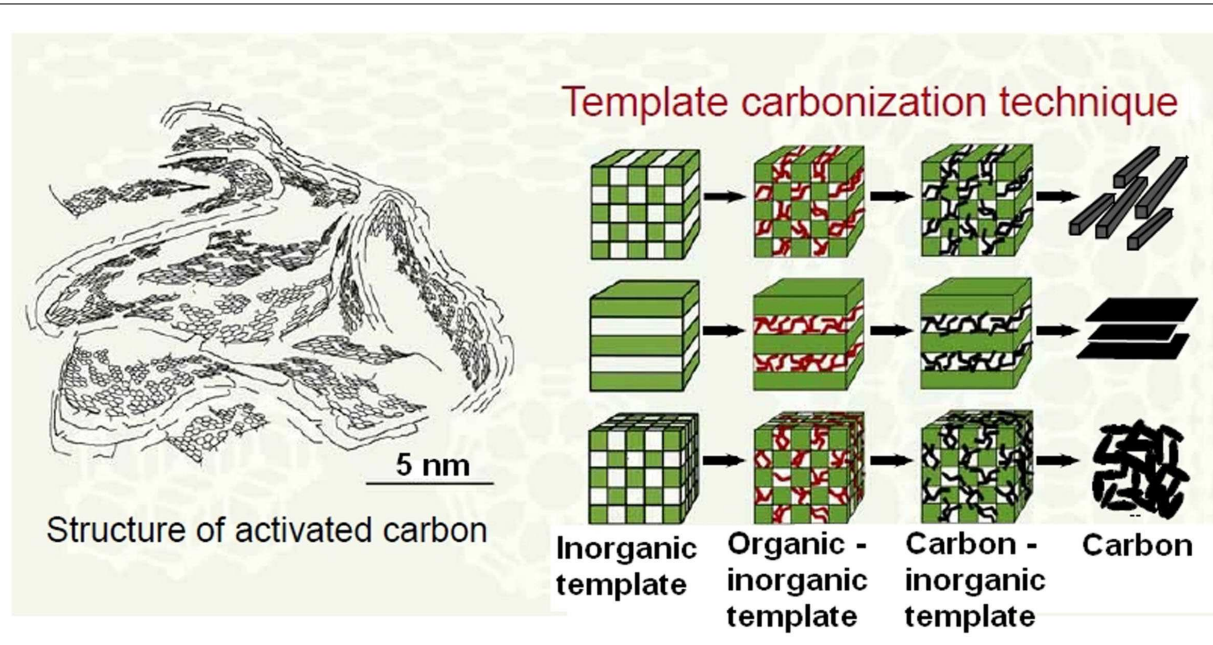

FIGURE 2 | Schematic depiction of template method (Kyotani, 2006) 

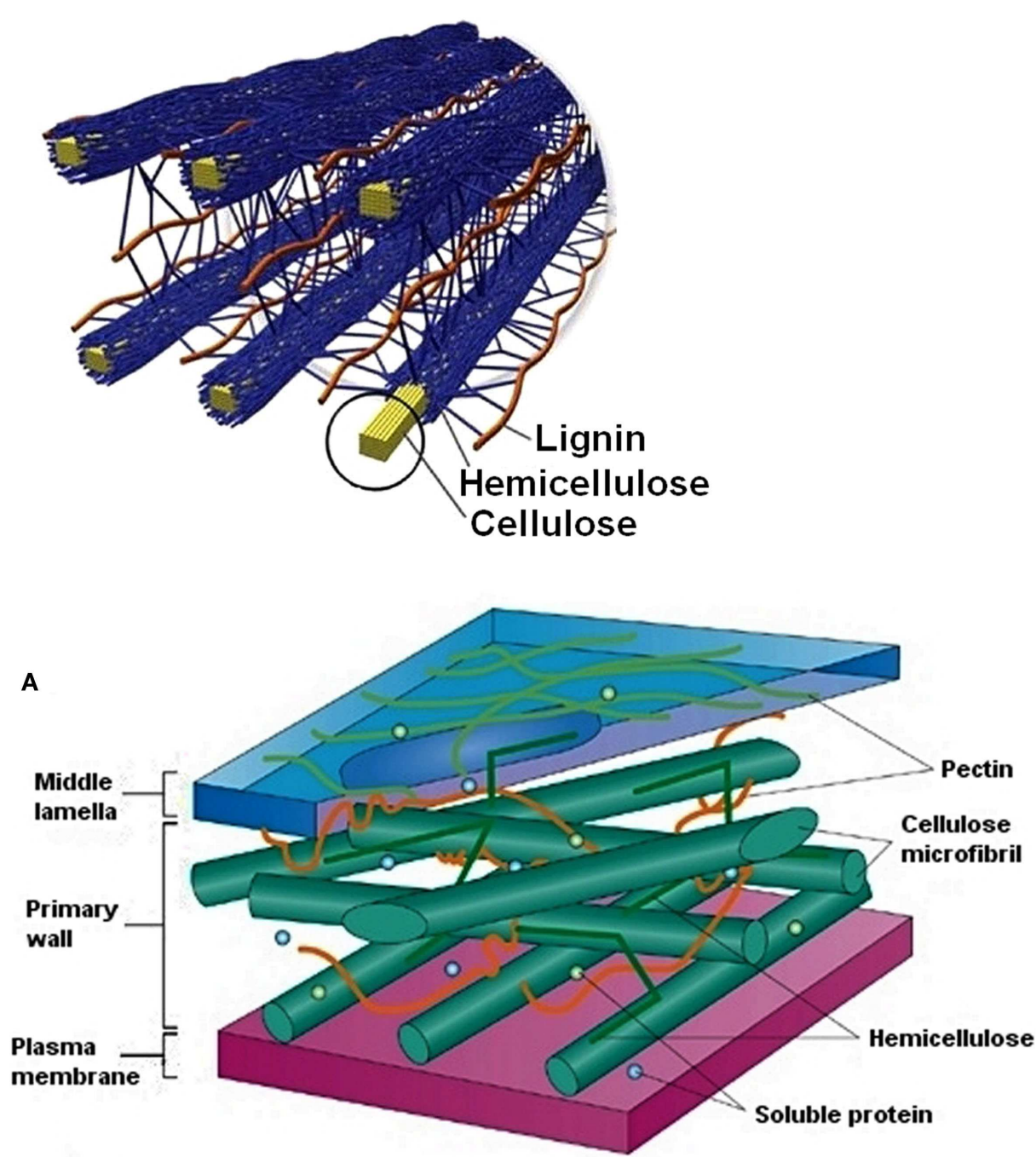

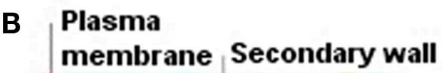

C

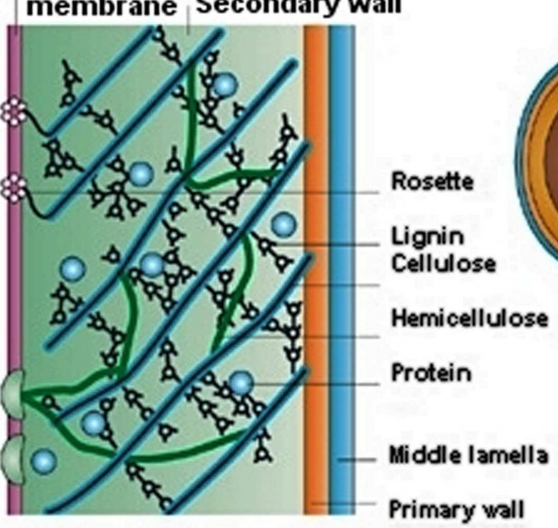

Secondary wall (\$3)

Secondary wall (\$2)

Secondary wall (\$1)

Primary wall

Middle lamella

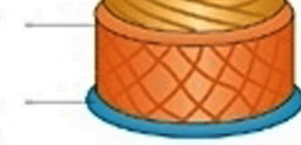

FIGURE 3 | Microscopic structure of wood [up - Doherty et al. (2011), down - Sticklen (2008)]. (A) Cell wall containing cellulose microfibrils, hemicellulose, pectin, lignin and soluble proteins. (B) Cellulose synthase enzymes are in the form of rosette complexes, which float in the plasma membrane. (C) Lignification occurs in the S1, S2 and S3 layers of the cell wall. 
decomposition involves the following stages (Kilzer and Broido, 1965):

- evaporation of physically bonded water $60-100^{\circ} \mathrm{C}$.

- dehydration of cellulose to "dehydrocellulose" in the range $200-280^{\circ} \mathrm{C}$.

- depolymerization of cellulose in competition with dehydration in the range $280-340^{\circ} \mathrm{C}$, resulting in the formation of volatiles.

- decomposition of dehydrocellulose into gases and char residue via an exothermic reaction that becomes dominant at about $320^{\circ} \mathrm{C}$. Splitting of birch cellulose molecules was estimated by Sergeeva and Vaivads (1954) as the range $299-389^{\circ}$ and a plateau the formation of stable substances was suggested to proceed between about 450 and $520^{\circ} \mathrm{C}$.

Our investigations (Cyganiuk et al., 2011) on carbonization of Salix viminalis wood confirm that also lignin decomposes intensively upon heat-treatment. The dry wood releases gases and vapors. The latter is easily condensate in form dark bio oil, which contains high amounts of polyphenols and their derivatives. The species are, in fact, basic building stones of lignin macromolecules released by thermal degradation of the matter (Olejniczak et al., 2012).

The lack of a natural soft template (hemicellulose and some other species) in pure cellulose delivered as a chemical reagent is the cause of low surface area and pore volume in the chars obtained by its heat-treatment (Norton et al., 1995). The parameters can be upgraded provided additional supporting measures are undertaken. The known measures supporting carbonization of pure cellulose like hydrothermal method and cellulose pre-oxidation are relatively well known from literature announcements (Norton et al., 1995; Sevilla and Fuertes, 2009; Guo and Fang, 2014). Both measures have oxidative nature, which let to improve surface parameters of activated carbon obtained from cellulose. For example, Norton et al. noticed a spectacular increase of specific surface area from 65 (carbonized pure cellulose from Sigma-Aldrich) to above $400 \mathrm{~m}^{2} / \mathrm{g}$ after pre-oxidation of cellulose prior to carbonization (Norton et al., 1995). Similar effect was ascribed to hydrogen chloride by McGhee et al. (1995) in the study on co-pyrolysis of PVC waste and a bio-precursor (wheat straw). In this case, the evolution of $\mathrm{HCl}$ from PVC waste considerably influenced the properties of carbon matrixes formed upon thermal decomposition of wheat straw (McGhee et al., 1995). However, it has to be stated that wheat straw is a material composed from three components, i.e., cellulose, hemicellulose, and lignin resembling wood composition and structure (Khan and Mubeen, 2012). Therefore, advanced structural parameters of straw-originated chars (similar to the ones of wood-originated chars) should be seen as resulting from the precursor structure, too.

The crucial role of cellulose and lignin in carbon matrix formation can be confirmed be some experiments with an example lignin-cellulose material, i.e., wood chips of Salix viminalis. The material, when carbonized in pristine state, instantly yields well developed surface area and total pore volume (Table S1 in Supplementary Material) (Lukaszewicz and Zielinski, 2011). The specific surface area of such obtained carbon approaches ca. $300 \mathrm{~cm}^{2} / \mathrm{g}$ and the carbons are microporous (Lukaszewicz and Zielinski, 2011).
Better structural properties can be achieved by a chemical activation, i.e., impregnation of the wood with typical acidic activators. In case of impregnation with 30-60\% w/w $\mathrm{H}_{3} \mathrm{PO}_{4}$ (prior to carbonization), the surface area of resulting chars exceeds $780 \mathrm{~m}^{2} / \mathrm{g}$. The influence of the acid on hemicellulose and lignin is a key reason of the observed structural parameters improvement. When orthophosphoric acid is added, dehydration of hemicellulose and lignin proceeds intensively and their thermal decomposition occurs in a narrower temperature range placed at lower temperatures. This means that such an acidic activation helps to remove hemicellulose (besides the action on lignin and cellulose), which is assumed to be a natural soft template (see Figure 3). As the matter of fact, othophosphoric acid interacts also with cellulose (partial dehydration and depolymerization) but not in the way which could negatively influence the subsequent formation of carbon matrix.

On the contrary, a base activation consisting in the saturation of Salix viminalis wood with a $\mathrm{KOH}$ solution $(2 \mathrm{M})$ prior to carbonization, leads to dramatically different results. Strong base like $\mathrm{KOH}$ intensively interacts with cellulose and lignin (in Salix viminalis wood) transforming them into water-soluble derivatives. The dissolution of cellulose in alkaline solution is highly dependent no time and temperature. At ca. $100^{\circ} \mathrm{C}$ cellulose can be dissolved in $70-80 \%$ after $15 \mathrm{~min}$ in $15 \% \mathrm{NaOH}$ solution (Zhang et al., 2013). This phenomenon confirms the importance of cellulose in carbon matrix formation. Therefore, a chemical destruction of cellulose in Salix viminalis wood (the action of $\mathrm{KOH}$ ) prior to its carbonization results in degraded structural parameters of resulting chars.

Similar situation occurs in case of other natural polymer chitosan, which is often called as "animal cellulose.” The term reflects a similarity between these two polymers, i.e., chitosan and cellulose. Chitosan is a biopolymer obtained by deacetylation of another commonly accessible biopolymer chitin. Chitin can be obtained as a by-product during processing of crustaceans (Crustacea). Chitosan structure is characteristic because of amino groups linked to the chain of six-member saccharide rings, i.e., poly(D)glucosamine. Thus, the polymer is naturally rich of nitrogen and possesses specific acid-base properties and chelation abilities directly resulting from the presence of $\mathrm{NH}_{2}$-groups. In general, chitosan structure resembles the structure of cellulose (Figure 4),
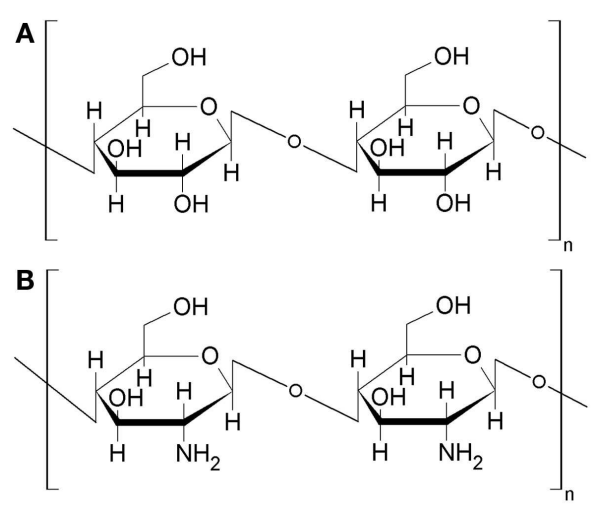

FIGURE 4 |The structure of cellulose (A) and chitosan (B) 


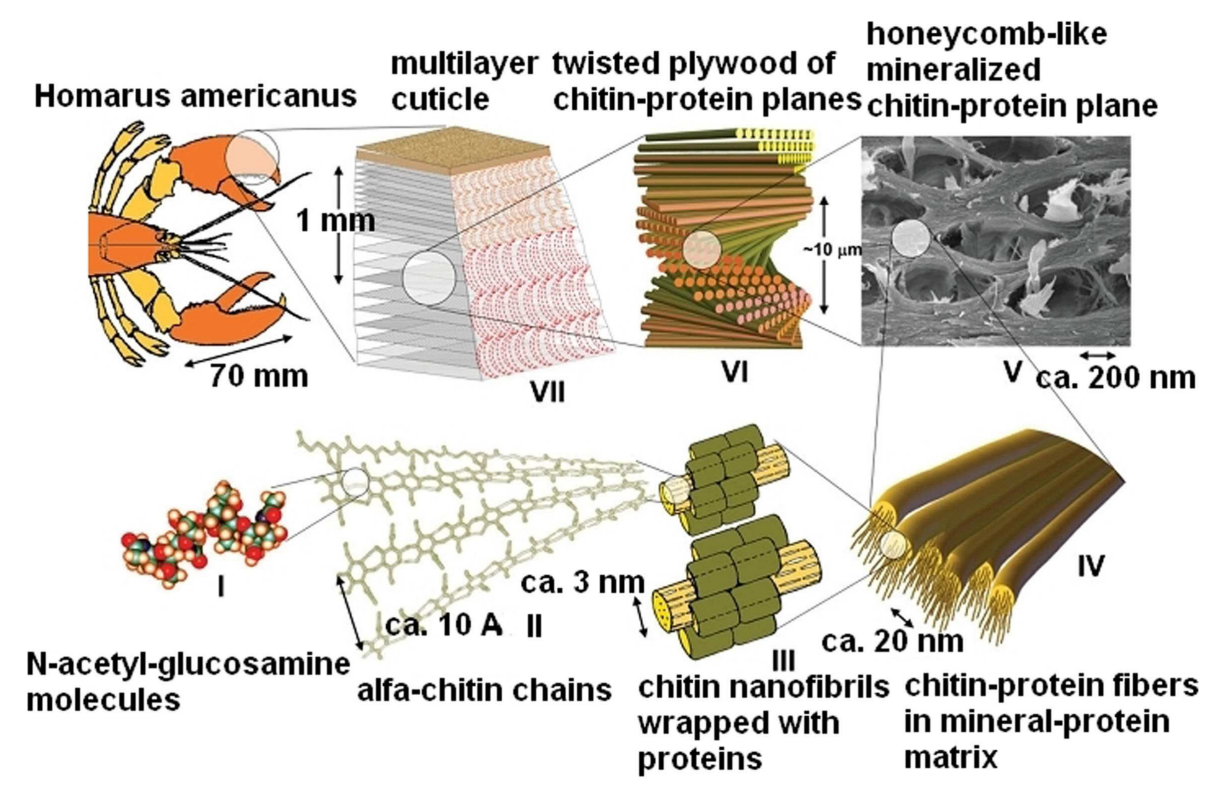

FIGURE 5 | Hierarchical structure of the lobster cuticle: (I)

$\mathrm{N}$-acetyl-glucosamine molecules, (II) antiparallel chains of a-chitin, (III) chitin-protein nanofibrils, (IV) chitin-protein fibers in a mineral-protein matrix (not shown), (V) cuticle with pore canal system (in-plane cross-section), (VI) twisted plywood structure, and (VII) three-layered cuticle (Nikolov et al., 2010). in which hydroxyl groups are present instead of amino groups. The similarity extends to the carbonization of chitosan, which (as cellulose) can not be easily transformed into a char of advanced structural properties just by a simple heat-treatment in oxygenfree conditions. An artificial template like $\mathrm{Na}_{2} \mathrm{CO}_{3}$ or $\mathrm{SiO}$ must be added to chitosan to upgrade structural parameters of chitosan derived chars (Kucinska et al., 2012; Olejniczak et al., 2013). The template is present in chitosan in the form of nanoparticles (ca. 10-50 nm diameter). After the removal of the template numerous cavities (pores) reveal their presence in the enhanced surface area and pore volume (Table S2 in Supplementary Material).

In the latter experiment, pure chitosan as pure cellulose was purchased and examined as a chemical reagent. Despite its biological origin, this biopolymer is extracted from its natural resource, i.e., chitin with the same consequences as in case of cellulose which is extracted form wood. In both cases, the original 3D structure of cellulose fibers and lignin domains in wood (Figure 3 ) as well as 3D arrangement of chitin fibrils in peptide-mineral matrix (Figure 5) was destroyed. Thus, the extraction process yields materials (cellulose and chitosan), which do not posses structures resembling the structures of wood and chitin. In the above sections, it was suggested that cellulose fibrils and lignin domains in wood were fixed in a porous 3D structure by hemicellulose, which behaved like soft template during carbonization. Additionally, the original structure of wood is a source of primary porosity of wood-originated chars since carbonization of sole wood components (no activators applied) yields non-porous chars. Looking for some further similarities, wood - chitin and cellulose-chitosan, chitin was subjected to carbonization hoping that it will yield porous chars on the contrary to the chars from pure chitosan.
Table S2 in Supplementary Material presents structural parameters of some chars obtained from chitin and chitosan. As expected, chitin assumed to behave analogously to wood, yields porous chars of advanced structural parameters, i.e., surface area and pore volume. In this case, chitin nanofibrils yield the carbon matrix, which is additionally rich of nitrogen which while mineral-protein matrix plays a role a template similarly to hemicellulose in wood and decomposes at lower temperatures.

\section{CONCLUSION}

Natural biomaterials like wood and chitin posses a unique 3D structure fixed by hemicellulose and peptides (correspondingly). The structure can be partially transferred to porous chars obtained by carbonization of the raw biomaterials. Cellulose and chitosan, which are extracted from the original 3D structure of wood and chitin, loose the ability to yield carbonaceous matrixes of advanced surface/structural parameters. However, cellulose and chitosan preserve the ability to form carbonaceous non-porous matrixes. The application of additional activation measures (oxidative carbonization, hydrothermal carbonization, application of templates, etc.) is inevitable to manufacture porous chars from cellulose and chitosan. It is also assumed that hemicellulose in wood and peptides in chitin behave like natural soft templates during carbonization of wood, i.e., the substances get volatized and vanish leaving empty spaces (pores) in carbon matrixes. The hypothesis is in part proven by independent experiments and already established knowledge but is still open for a further discussion and experimental verification. 


\section{SUPPLEMENTARY MATERIAL}

The Supplementary Material for this article can be found online at http://www.frontiersin.org/Journal/10.3389/fmats.2015.00020/ abstract

\section{REFERENCES}

Aygün, A., Yenisoy-Karakas, S., and Duman, I. (2003). Production of granular activated carbon from fruit stones and nutshells and evaluation of their physical, chemical, and adsorption properties. Microporous Mesoporous Mater. 66, 189-195. doi:10.1016/j.micromeso.2003.08.028

Cyganiuk, A., Gorska, O., Olejniczak, A., and Lukaszewicz, J. P. (2012). Carbon molecular sieve fabrication from "green" renewal wood resources. J. Anal. Appl. Pyrolysis 98, 15-21. doi:10.1016/j.jaap.2012.06.008

Cyganiuk, A., Olejniczak, A., Kucinska, A., Klimkiewicz, R., and Lukaszewicz, J. P. (2011). "Energetic willow (Salix viminalis) - unconventional applications," in Renewable Energy, Vol. 2, ed. M. Nayeripour (Rijeka: CRO, InTech Open Access), 181-208.

Daifullah, A. A. M., and Girgis, B. S. (2003). Impact of surface characteristics of activated carbon on adsorption of BTEX. Colloids Surface A. Physiochem. Eng. Asp. 214, 181-193. doi:10.1016/S0927-7757(02)00392-8

Doherty, W. O. S., Mousavioun, P., and Fellows, C. M. (2011). Value-adding to cellulosic ethanol: Lignin polymers. Ind. Crop. Prod. 33, 259-276. doi:10.1016/j. indcrop.2010.10.022

Guo, F., and Fang, Z. (2014). Shape-controlled synthesis of activated bio-chars by surfactant-templated ionothermal carbonization in acidic ionic liquid and activation with carbon-diooxide. Bioresources 9, 3369-3383. doi:10.15376/biores.9. 2.3369-3383

Khan, T. S., and Mubeen, U. (2012). Wheat straw: a pragmatic overview. Curr. Res. J. Biol. Sci 4, 673-675.

Kilzer, F. J., and Broido, A. (1965). Speculations on the nature of cellulose pyrolysis. Pyrodynamics 2, 151-163.

Kucinska, A., Cyganiuk, A., and Lukaszewicz, J. P. (2012). A microporous and high surface area active carbon obtained by the heat-treatment of chitosan. Carbon N. Y. 50, 3098-3101. doi:10.1016/j.carbon.2012.02.042

Kyotani, T. (2006). Synthesis of various types of nano carbons using the template technique. Bull. Chem. Soc. Jpn. 79, 1322-1337. doi:10.1246/bcsj.79.1322

Liu, J., Su, F., Guo, W., Tian, X. N., Zhao, X. S., and Zhou, Z. (2007). Template approaches to preparing porous carbon. Chem. Phys. Carbon 30, 63-128. doi:10.1201/9781420042993.ch2

Lukaszewicz, J. P., and Zielinski, K. (2011). Durability and narrow pore size distribution (PSD) of carbons fabricated from Salix viminalis wood. Chem. Proc. Eng 32, 195-201. doi:10.2478/v10176-011-0015-5

McGhee, B., Norton, F., Snape, C. E., and Hall, P. J. (1995). The copyrolysis of poly(vinylchloride) with cellulose derived materials as a model for municipal waste derived chars. Fuel 74, 28-31. doi:10.1016/0016-2361(94)P4326-W

Nikolov, S., Petrov, M., Lymperakis, L., Friak, M., Sachs, C., Fabritius, H.-O., et al. (2010). Revealing the design principles of high-performance biological composites using $\mathrm{Ab}$ initio and multiscale simulations: the example of Lobster cuticle. Adv. Mater. 22, 519-526. doi:10.1002/adma.200902019

Norton, F. J., Love, G. D., Mackinnon, A. J., and Hall, P. J. (1995). Mechanisms of char production from oxidized cellulose. J. Mater. Sci. 30, 596-600 doi:10.1007/BF00356316
Olejniczak, A., Kucinska, A., Cyganiuk, A., and Lukaszewicz, J. P. (2012). Effect of Salix viminalis pyrolysis-derived antioxidants on oxidative stability of diesters and diester-poly- $\alpha$-olefine mixtures. Ind. Eng. Chem. Res. 51, 5117-5123. doi:10.1021/ie2007054

Olejniczak, A., Lezanska, M., Wloch, J., Kucinska, A., and Lukaszewicz, J. P. (2013). New nitrogen-containing mesoporous carbons prepared from chitosan. J. Mater. Chem. A 1, 8961-8967. doi:10.1039/c3ta11337j

Roberts, A. F. (1971). "Problems associated with the theoretical analysis of the burning of wood," in Proc. $13^{\text {th }}$ Int. Symposium on Combustion, ed. H. G. Barnes (Pittsburgh, PA: The Combustion Institute), 893-903.

Schröder, E., Thomauske, K., Oechsler, B., Herberger, S., Baur, S., and Hornung, A. (2011). "Activated carbon from waste biomass," in Progress in Biomass and Bioenergy Production, ed. S. Shaukat (Rijeka: CRO, InTech), 333-356.

Sergeeva, V. N., and Vaivads, A. (1954). Thermographic study of the pyrolysis of wood and its constituents. Latvijas PSR Zinat, Akad. Vetis. 86, 103-108.

Sevilla, M., and Fuertes, A. B. (2009). The production of carbon materials by hydrothermal. Carbon N. Y. 47, 2281-2289. doi:10.1016/j.carbon.2009. 04.026

Sticklen, M. B. (2008). Plant genetic engineering for biofuel production: towards affordable cellulosic ethanol. Nat. Rev. Genet. 9, 433-443. doi:10.1038/ $\operatorname{nrg} 2336$

Terzyk, A. P., Furmaniak, S., Harris, P. J. F., Gauden, P. A., Wloch, J., Kowalczyk, P., et al. (2007). How realistic is the pore size distribution calculated from adsorption isotherms if activated carbon is composed of fullerene-like fragments? Phys. Chem. Chem. Phys. 9, 5919-5927. doi:10.1039/b710552e

Zhang, S., Wang, W.-C., Li, F.-X., and Yu, J. Y. (2013). Swelling and dissolution of cellulose in $\mathrm{NaOH}$ aqueous solvent system. Cellulose Chem. Technol. 47, 671-679.

Zhang, S., Xu, L., Liu, H., Zhao, Y., Zhang, Y., Wang, Q., et al. (2009). A dual template method for synthesizing hollow silica spheres with mesoporous shells. Mater. Lett. 63, 258-259. doi:10.1016/j.matlet.2008.10.004

Conflict of Interest Statement: The authors declare that the research was conducted in the absence of any commercial or financial relationships that could be construed as a potential conflict of interest.

Received: 18 November 2014; paper pending published: 06 December 2014; accepted: 26 February 2015; published online: 16 March 2015.

Citation: Ilnicka A and Lukaszewicz JP (2015) Discussion remarks on the role of wood and chitin constituents during carbonization. Front. Mater. 2:20. doi: 10.3389/fmats.2015.00020

This article was submitted to Carbon-Based Materials, a section of the journal Frontiers in Materials.

Copyright ( $) 2015$ Ilnicka and Lukaszewicz. This is an open-access article distributed under the terms of the Creative Commons Attribution License (CC BY). The use, distribution or reproduction in other forums is permitted, provided the original author(s) or licensor are credited and that the original publication in this journal is cited, in accordance with accepted academic practice. No use, distribution or reproduction is permitted which does not comply with these terms. 